\title{
Molecular evidence supports simultaneous association of the achlorophyllous orchid Chamaegastrodia inverta with ectomycorrhizal Ceratobasidiaceae and Russulaceae
}

Lorenzo Pecoraro ${ }^{1 *}$ (D, Xiao Wang ${ }^{1}$, Giuseppe Venturella² ${ }^{2}$ Wenyuan Gao ${ }^{1}$, Tingchi Wen ${ }^{3}$, Yusufjon Gafforov ${ }^{4}$ and Vijai Kumar Gupta ${ }^{5}$

\begin{abstract}
Background: Achlorophyllous orchids are mycoheterotrophic plants, which lack photosynthetic ability and associate with fungi to acquire carbon from different environmental sources. In tropical latitudes, achlorophyllous forest orchids show a preference to establish mycorrhizal relationships with saprotrophic fungi. However, a few of them have been recently found to associate with ectomycorrhizal fungi and there is still much to be learned about the identity of fungi associated with tropical orchids. The present study focused on mycorrhizal diversity in the achlorophyllous orchid C. inverta, an endangered species, which is endemic to southern China. The aim of this work was to identify the main mycorrhizal partners of $C$. inverta in different plant life stages, by means of morphological and molecular methods.

Results: Microscopy showed that the roots of analysed C. inverta samples were extensively colonized by fungal hyphae forming pelotons in root cortical cells. Fungal ITS regions were amplified by polymerase chain reaction, from DNA extracted from fungal mycelia isolated from orchid root samples, as well as from total root DNA. Molecular sequencing and phylogenetic analyses showed that the investigated orchid primarily associated with ectomycorrhizal fungi belonging to a narrow clade within the family Ceratobasidiaceae, which was previously detected in a few fully mycoheterotrophic orchids and was also found to show ectomycorrhizal capability on trees and shrubs. Russulaceae fungal symbionts, showing high similarity with members of the ectomycorrhizal genus Russula, were also identified from the roots of C. inverta, at young seedling stage. Ascomycetous fungi including Chaetomium, Diaporthe, Leptodontidium, and Phomopsis genera, and zygomycetes in the genus Mortierella were obtained from orchid root isolated strains with unclear functional role.
\end{abstract}

(Continued on next page)

\footnotetext{
* Correspondence: lorenzo.pecoraro@gmail.com

'School of Pharmaceutical Science and Technology, Health Sciences

Platform, Tianjin University, 92 Weijin Road, Nankai District, Tianjin 300072,

China

Full list of author information is available at the end of the article
}

(C) The Author(s). 2020 Open Access This article is licensed under a Creative Commons Attribution 4.0 International License, which permits use, sharing, adaptation, distribution and reproduction in any medium or format, as long as you give appropriate credit to the original author(s) and the source, provide a link to the Creative Commons licence, and indicate if changes were made. The images or other third party material in this article are included in the article's Creative Commons licence, unless indicated otherwise in a credit line to the material. If material is not included in the article's Creative Commons licence and your intended use is not permitted by statutory regulation or exceeds the permitted use, you will need to obtain permission directly from the copyright holder. To view a copy of this licence, visit http://creativecommons.org/licenses/by/4.0/ The Creative Commons Public Domain Dedication waiver (http://creativecommons.org/publicdomain/zero/1.0/) applies to the data made available in this article, unless otherwise stated in a credit line to the data. 


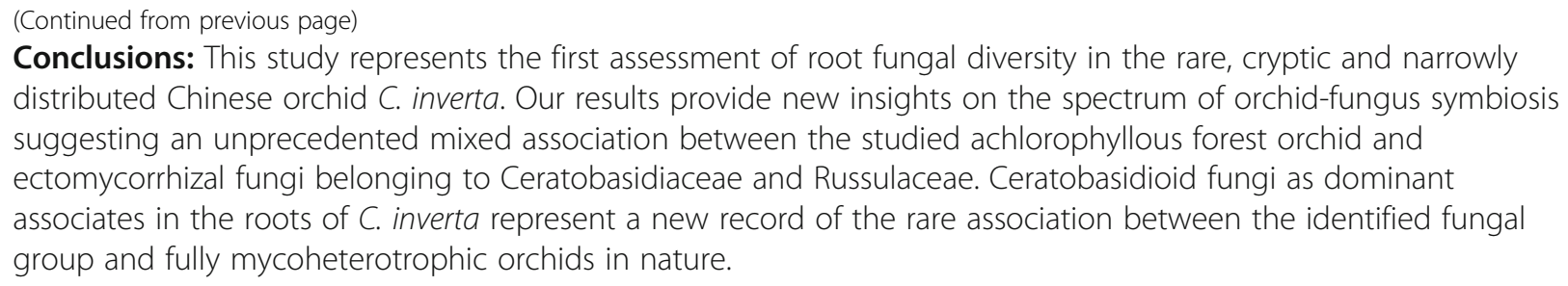

Keywords: Achlorophyllous orchids, Ceratobasidiaceae, Ectomycorrhizal fungi, Endangered species, Orchid mycorrhiza, Plant-fungus interactions, Mycoheterotrophy, Russula

\section{Background}

Mycoheterotrophic plants are associated with fungi that support their heterotrophy with varying extents. Indeed, these peculiar plants acquire carbon through mycorrhizal association with fungal mycelia fetching organic compounds from different environmental sources [1]. Among mycoheterotrophs, achlorophyllous plants, represented by more than 400 vascular species, are fully heterotrophic, since they are not able to photosynthesize and rely solely on carbon from their mycorrhizal fungi [2]. Some plants that contain chlorophyll are partially heterotrophic, because they respire more carbon than they fix and thus obtain part of their organic nutrients heterotrophically via associated fungi and part autotrophically by photosynthesis [3]. In addition, many plants are mycoheterotrophic only during their early stage of development, but become autotrophic when fully developed [1].

The Orchidaceae family is particularly predisposed to mycoheterotrophy, encompassing all known levels of nutritional dependence upon fungi. All orchids are mycoheterotrophic during their establishment phase, since they produce extremely small seeds that lack the nutrient reserves necessary for early growth. For this reason, orchid seed germination and the following achlorophyllous protocorm stage depend on the presence of a fungal partner that provides water, mineral nutrients and organic carbon to the juvenile plant [4]. At the adult stage, most orchid species become fully autotrophic, and although they maintain a relationship with their root associated fungi, this is no longer for carbon nutrition, but just for water and mineral uptake [5]. In contrast, a significant number of forest orchids that develop a photosynthetic apparatus at adulthood remain dependent on both organic and inorganic fungal nutrients under low light availability [6]. This dual nutritional strategy combining mycoheterotrophy and photoassimilation is known as partial mycoheterotrophy or mixotrophy [7]. Recent studies based on stable isotope analysis, including ${ }^{2} \mathrm{H},{ }^{13} \mathrm{C},{ }^{15} \mathrm{~N}$ and ${ }^{18} \mathrm{O}$, for understanding nutrient exchange between orchids and fungi, have shown that partial mycoheterotrophy plays a far greater role than previously assumed, not only in forest orchids, but even in orchids growing in open habitats with full light conditions [8]. Achlorophyllous orchids are at the extreme point of plant's nutritional reliance on mycorrhizal fungi, with about 235 species, i.e. more than $50 \%$ of all fully mycoheterotrophic plants, that completely lack photosynthetic capability even at maturity, thus being obligately mycoheterotrophic throughout their lifetime [9]. Regarding fungal diversity in orchid mycorrhizae, fully autotrophic orchids generally associate with a wide range of basidiomycetous fungi of the form-genus Rhizoctonia, including soil saprotrophs, plant endophytes and pathogens, as well as fungi with poorly known trophic roles $[4,10]$. Mixotrophic and fully mycoheterotrophic orchids recruit instead ascomycetes and basidiomycetes having access to large and persistent carbon sources, such as ectomycorrhizal fungal species that simultaneously colonize surrounding tree roots $[7,11]$. The latter case constitutes a peculiar tripartite mycorrhizal association in which a shared fungal mycelium transfers photosynthates from the tree to the orchid, thus the orchid indirectly exploiting the tree as a carbon source [12]. Mycorrhizal specificity, represented by the phylogenetic diversity of fungi associated with a particular plant, is low in the majority of green fully photosynthetic orchids, where an orchid species establishes mycorrhizae with several phylogenetically distant fungal species in the Rhizoctonia complex [13]. Sometimes protocorms are associated with a smaller range of fungal symbionts than adult plants [5]. Mixotrophic orchids establish either specific or non-specific mycorrhizal associations, sometimes with the coexistence of rhizoctonias and ectomycorrhizal fungi in the same plant species [14-16]. By contrast, the level of specificity is normally very high in achlorophyllous orchids. These orchids often associate with a single fungal clade constituted by a genus or by a lower rank taxon, and the fungi involved, with a few exceptions, are not Rhizoctonia species [17, 18]. In particular, achlorophyllous orchids from temperate areas of northern latidudes have been shown in several works to associate with non-Rhizoctonia ectomycorrhizal fungi that allow the orchid to establish an indirect below 
ground connection with nearby autotrophic plants. For instance, the Eurasian orchid species Epipogium aphyllum has been found associated with basidiomycetes mainly belonging to the ectomycorrhizal genus Inocybe [18]. In tropical latitudes instead, achlorophyllous orchids have been recently shown to establish mycorrhizal relationships with non-Rhizoctonia saprotrophic fungi. Basidiomycetes belonging to the saprobic Coprinaceae family were found in association with the Asian achlorophyllous orchid Eulophia zollingeri [19], Gymnopus-related fungal taxa were molecularly identified in the Australian orchid Erythrorchis cassythoides [20], litterdecaying Mycena in the Caribbean Wullschlaegelia aphylla [21] and the Japanese Gastrodia confusa [17], while Marasmius mycobionts were detected in Gastrodia sesamoides from Australia [22]. This peculiar preference for fungal saprotrophs is particularly interesting in tropical orchid species phylogenetically close to temperate orchids, which are instead associated with ectomycorrhizal fungi. For example, the tropical orchid $E$. roseum, showing a very close phylogenetic relationship with the above-mentioned Eurasian species E. aphyllum, is associated with saprotrophic Psathyrellaceae [23, 24]. The latter orchid-fungus relationship provides the evidence that the establishment of associations between achlorophyllous orchids and saprobic versus mycorrhizal fungi is not phylogenetically constrained. Environmental factors, such as the warm and humid climate occurring in tropical areas, may allow saprotrophic fungi to extend their growing period and improve their decaying activity on the available organic substrates, thus providing a surplus of nutrients that can be transferred to the fully mycoheterotrophic orchid partners [25]. However, a few exceptions are known. For instance, Roy et al. [26] investigated three Asiatic mycoheterotrophic Neottieae species in Thailand and found that all were associated with ectomycorrhizal fungi, such as Thelephoraceae, Russulaceae and Sebacinales. In a study conducted on fully mycoheterotrophic orchids from sub-tropical Asia, six out of seven analysed orchid species established mycorrhizal relationships with either wood- or litter-decaying saprotrophic fungi, while only one species was associated with ectomycorrhizal fungi [27]. Another exception is represented by the Asian non-photosynthetic orchid species Chamaegastrodia shikokiana, which was found to associate with ectomycorrhizal fungi belonging to Ceratobasidiaceae. Mycobionts isolated from C. shikokiana were able to form ectomycorrhiza in vitro on seedlings of Abies firma, suggesting that the studied orchid may depend on nutrients supplied from the tree species through the hyphae of the mycorrhizal fungi in nature [28].

The present study focused on C. inverta (W.W. Smith) Seidenfaden, one of the five achlorophyllous orchid species in the genus Chameagastrodia, which is endemic to
Yunnan and Sichuan provinces, southern China, usually growing in damp places in montane forests (1200-2600 $m$ a.s.l.) [29]. The aim of this work was to identify the main mycorrhizal partners of $C$. inverta in different plant life stages, by means of morphological and molecular methods. A better understanding of mycorrhizal strategies in orchid species belonging to the genus Chamaegastrodia, such as C. inverta, would clarify the biology of achlorophyllous orchids and would be of relevance to future in situ or ex situ conservation activities of this endangered species.

\section{Results}

\section{Mycorrhizal root morphology of $C$. inverta}

Light microscopy on thin sections showed that the roots of all analysed C. inverta samples (Fig. 1) were extensively colonized by fungal hyphae. Characteristic dense intracellular hyphal coils (pelotons) were observed in most orchid root cortical cells (Fig. 2a-b). The majority of pelotons appeared intact and completely undigested (Fig. 2a-b). A dominant mycelial morphology characterized the observed pelotons, mainly constituted by dark, septate, thick-walled (7.5-10.5 $\mu \mathrm{m}$ in diameter) hyphae, frequently showing branches produced at right angles to the main hypha, the branch hypha being slightly constricted at the branch origin, and septum often occurring near the branch origin (Fig. 2c-d).

\section{Fungal isolation}

Attempts to isolate in vitro single pelotons extracted from $C$. inverta root cells were in most cases unsuccessful. No hyphal growth was observed from the fungal coils transferred on PDA medium, with a single exception from orchid sample 5 . On the contrary, the majority of surface-sterilized root portions yielded fungal mycelia that could be assigned to 32 main morphological types of ascomycetous and zygomycetous fungi by macro- and microscopic observations. These orchid root endophytes were subsequently identified using molecular taxonomy, because the paucity of distinctive morphological characters did not allow a clear taxonomic delimitation, based on microscopy. However, the morphology of isolated mycelia was in most cases completely different from the above-mentioned dominant hyphal morphology observed in the root sections by the microscope.

\section{Identification of $C$. inverta mycorrhizal symbionts and other endophytes}

Molecular analysis allowed the identification of fungi associated with $C$. inverta roots. Sequences were produced from amplicons of both fungal cultures and total root DNA, using the fungal-specific primer pair ITS1-OF/ ITS4-OF. These primers successfully yielded sequences from all the 32 fungal isolates and the 8 analysed plants. 


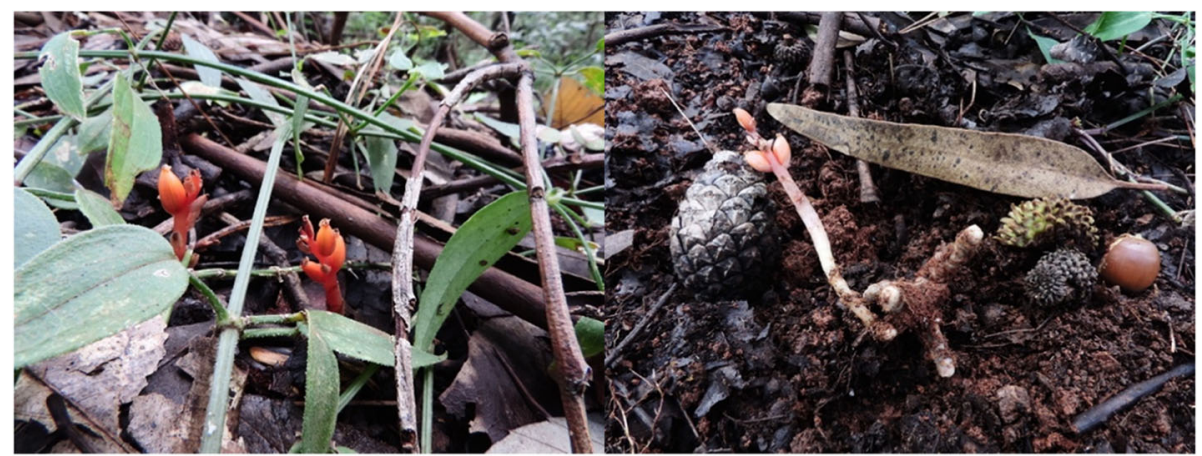

a

b

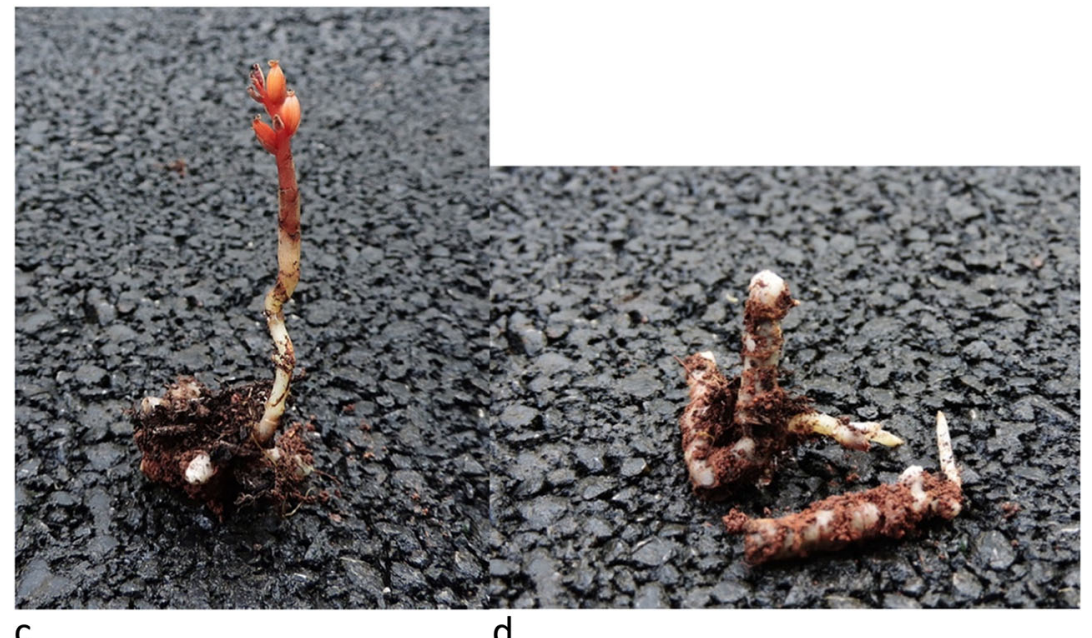

Fig. 1 Chamaegastrodia inverta adult and completely developed plants $(\mathbf{a}, \mathbf{b}, \mathbf{c})$ and young hypogeous individuals (seedlings, d). Green leaves and stems represented in Fig. 1 a belong to non-orchid surrounding vegetation in C. inverta habitat

Amplicon electrophoretic profiles displayed high intensity bands from 600 to $800 \mathrm{bp}$. The general primer pair ITS1F/ITS4 gave, instead, less consistent amplification, and in some cases, never produced any amplicon, or just amplified the orchid plant DNA (data not shown).

Total root DNA sequencing revealed that mycorrhizal tissue was dominated by fungi belonging to the family Ceratobasidiaceae (Table 1). For 7 out of the total 8 investigated $C$. inverta plants, amplified sequences were related to Ceratobasidium sequences in GenBank. The young orchid plant (seedling) sample 6 yielded sequences 6a (accession no. MT278316) and 6b (MT278317) with close identity to GenBank accession sequences of Russulaceae and Ceratobasidiaceae, respectively (Table 1 ).

Phylogenetic analysis clarified the relationships of $C$. inverta root-associated fungi within Russulaceae and Ceratobasidiaceae. Sequences retrieved from the studied orchid plants could be aligned with fungal sequences from various orchid and non-orchid plant hosts, isolated strains, and sporophores. A neighbour-joining tree revealed that all Ceratobasidium-like sequences obtained in this study clustered into a single well-supported clade (Fig. 3) and are closely related to ceratobasidioid fungi previously found in the rhizome of Chamaegastrodia shikokiana in Japan and in ectomycorrhizal root tips in China. These fungi formed a clade with $100 \%$ bootstrap support with another member of Ceratobasidiaceae isolated from the Australian mycoheterotrophic orchid Rhizanthella gardneri (Fig. 3). The phylogenetic tree from the Russulaceae dataset showed that the sequence amplified from roots of C. inverta plant sample 6 fell in a cluster including Russula cerolens (that was the closest match) R. pectinata and R. insignis (Fig. 4).

Apart from these basidiomycetes identified from total root DNA, sequences of ascomycetous and zygomycetous fungi were obtained from the isolated strains (Table 2). Among them, sequences corresponding to the genus Mortierella, in the Mortierellaceae family of Mucoromycota were most commonly recovered from $46.8 \%$ of cultured mycelia, including the sole strain obtained from peloton (sample 5, accession no. MT278348), whereas $25 \%$ of isolated fungi yielded sequences with very high ITS similarity to Phomopsis 




a

b

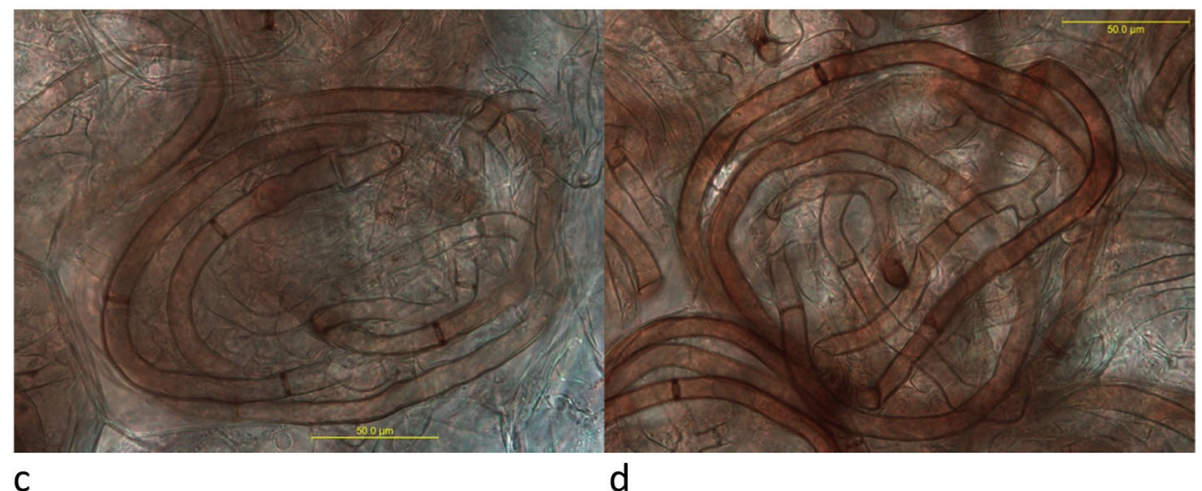

Fig. 2 Microscopic characteristics of mycorrhizal roots in Chamaegastrodia inverta. a Hyphal coils (pelotons) extracted from cortical cells. b Fungal pelotons inside orchid root cells. c, $\mathbf{d}$ Details of mycelial morphology characterizing pelotons, with dark, septate, thick-walled hyphae, showing $90^{\circ}$ branching, constriction at branch points, and septa near branch origins

species, belonging to the family Diaporthaceae of Ascomycota (Table 2). In the latter family was also found the best match for sequences obtained from $18.7 \%$ of isolates, belonging to the genus Diaporthe. Other ascomycetes from the genera Leptodontidium (Leptodontidiaceae family) and Chaetomium (Chaetomiaceae) were also sporadically found (Table 2).

\section{Discussion}

This study represents the first assessment of root fungal diversity in the rare, cryptic, and narrowly distributed Chinese orchid species Chamaegastrodia inverta. Microscopic analysis, showing the heavy presence of fungal pelotons in the root cortical cells of all studied orchid samples, provided the first evidence of the establishment of mycorrhizal associations in C. inverta. The observed extent of fungal colonization in the orchid mycorrhizal roots was not surprising, given the achlorophyllous condition of the investigated plant species. The studied orchid was expected to be wholly mycoheterotrophic and therefore highly dependent on soil fungi for its nutrition, based on results showed from the previously studied member of the genus Chamaegastrodia, C. shikokiana in Japan [28], and the general mycorrhizal condition of non-photosynthetic forest orchids $[1,30]$.
The use of different experimental approaches, including morphological analysis combined with molecular sequencing, following both culture-dependent methods and direct total orchid root DNA amplification, allowed the detection and identification of $C$. inverta rootassociated fungi, in different plant life stages. Results showed that the primary mycorrhizal symbionts of $C$. inverta are within the family Ceratobasidiaceae. This family is included in the diverse group of Rhizoctonialike fungi, which comprises a range of rather distantly related fungal taxa characterised by homogenous asexual stage hyphal morphology $\left(90^{\circ}\right.$ branching of hyphae, a constriction at the branch point, and a septum near the point of origin in the branch hyphae), as well as by a common significant predisposition to establish mycorrhizal symbiosis with orchids $[4,31,32]$. The morphology of mycelia forming pelotons in the root cells of analysed C. inverta individuals, showing typical Rhizoctonia features, is consistent with molecular identification of Ceratobasidiaceae fungal symbionts. Ceratobasidioid fungi have been previously found to associate with several other orchids including both tropical and temperate species [32-34]. Members of this fungal family have been recognized as important associates in epiphytic orchids belonging to different genera, such as Oncidium 
Table 1 Fungal diversity molecularly detected in Chamaegastrodia inverta roots, from extracted total root DNA

\begin{tabular}{|c|c|c|c|c|c|}
\hline C. inverta sample & GenBank code & Best BLAST match(es) & Accession code & Overlap length & $\%$ match \\
\hline \multirow[t]{2}{*}{ 1b (adult) } & MT278309 & Vouchered mycorrhizae (Basidiomycota) & AB303058 & 1160 & $98 \%$ \\
\hline & & Uncultured Ceratobasidium & JQ991678 & 1096 & $99 \%$ \\
\hline \multirow[t]{3}{*}{ 2b (adult) } & MT278310 & Vouchered mycorrhizae (Basidiomycota) & AB303057 & 1162 & $98 \%$ \\
\hline & & Uncultured Ceratobasidium & JQ991678 & 1096 & $99 \%$ \\
\hline & & Ceratobasidium sp. & GQ175299 & 1081 & $96 \%$ \\
\hline \multirow[t]{2}{*}{ 3b (adult) } & MT278311 & Vouchered mycorrhizae (Basidiomycota) & AB303057 & 1188 & $98 \%$ \\
\hline & & Ceratobasidium sp. & GQ175299 & 1122 & $96 \%$ \\
\hline \multirow[t]{3}{*}{ 4a (adult) } & MT278312 & Vouchered mycorrhizae (Basidiomycota) & AB303058 & 1155 & $98 \%$ \\
\hline & & Uncultured Ceratobasidium & JQ991678 & 1090 & $99 \%$ \\
\hline & & Ceratobasidium sp. & GQ175299 & 1068 & $95 \%$ \\
\hline \multirow[t]{3}{*}{$4 b$ (adult) } & MT278313 & Vouchered mycorrhizae (Basidiomycota) & AB303058 & 2055 & $98 \%$ \\
\hline & & Uncultured Ceratobasidium & JQ991678 & 1994 & $99 \%$ \\
\hline & & Ceratobasidium sp. & GQ175299 & 1920 & $96 \%$ \\
\hline \multirow[t]{3}{*}{$5 a$ (adult) } & MT278314 & Vouchered mycorrhizae (Basidiomycota) & AB303058 & 1088 & $96 \%$ \\
\hline & & Uncultured Ceratobasidium & JQ991678 & 1029 & $97 \%$ \\
\hline & & Ceratobasidium sp. & GQ175299 & 1002 & $94 \%$ \\
\hline \multirow[t]{3}{*}{$5 b$ (adult) } & MT278315 & Vouchered mycorrhizae (Basidiomycota) & AB303057 & 1129 & $97 \%$ \\
\hline & & Uncultured Ceratobasidium & JQ991678 & 1062 & $98 \%$ \\
\hline & & Ceratobasidium sp. & GQ175299 & 1048 & $95 \%$ \\
\hline 6a (seedling) & MT278316 & Russula cerolens & KX095042 & 1203 & $98 \%$ \\
\hline \multirow[t]{2}{*}{ 6b (seedling) } & MT278317 & Vouchered mycorrhizae (Basidiomycota) & AB303058 & 1138 & $98 \%$ \\
\hline & & Uncultured Ceratobasidium & JQ991678 & 1079 & $98 \%$ \\
\hline \multirow[t]{3}{*}{ 7a (seedling) } & MT278318 & Vouchered mycorrhizae (Basidiomycota) & AB303058 & 1155 & $98 \%$ \\
\hline & & Uncultured Ceratobasidium & JQ991678 & 1090 & $99 \%$ \\
\hline & & Ceratobasidium sp. & GQ175299 & 1068 & $96 \%$ \\
\hline 8a (seedling) & MT278319 & Phomopsis sp. & KF428571 & 1161 & $99 \%$ \\
\hline
\end{tabular}

BLAST search closest matches of fungal internal transcribed spacer DNA sequences amplified from C. inverta. Sample GenBank accession codes, accession codes for the closest GenBank matches, sequence identity, and overlap of each match are reported

[35], Ionopsis and Tolumnia [36, 37], as well as in terrestrial orchids, of both forest and meadow habitats, including Goodyera [38-40], Anacamptis, Cephalanthera and Orchis [16, 34, 41]. Although mycorrhizal associations with Ceratobasidiaceae involve orchids with very different biogeographical and ecological features, the great majority of orchid species that have been found to establish a trophic relationship with Ceratobasidiaceae fungi belong to the same physiological category of green orchids, including species with different degrees of photosynthetic capability, from fully autotrophic to mixotrophic species [8, 42, 43]. Achlorophyllous nonphotosynthetic orchids, instead, are almost completely excluded from mycorrhizal partnerships with Ceratobasidiaceae, with very few exceptions $[28,44]$. Our finding of ceratobasidioid fungi as dominant associates in the roots of the achlorophyllous forest orchid $C$. inverta represents a new record of the rare association between the identified fungal group and fully mycoheterotrophic orchids in nature. Phylogenetic relationships reconstructed from rDNA sequence information suggest that the $C$. inverta associated Ceratobasidiaceae have limited genetic diversity and likely belong to the same species (Fig. 3). Chamaegastrodia inverta mycobionts are phylogenetically close to a peculiar group of Ceratobasidiaceae showing ectomycorrhizal capability, such as the fungi previously found in C. shikokiana in Japan, which were also able to form ectomycorrhizas on the rootlets of the woody plant species Abies firma sedlings in pot culture [28], and the fungi associated with the Australian subterranean orchid (flowering below ground) Rhizanthella gardneri [44]. Mycorrhizal fungi, isolated from pelotons extracted from the rhizomes of the latter orchid species, were tested by Bougoure and collaborators for their ability to form ectomycorrhizal associations with several plant species belonging to the genus Melaleuca, which resulted in the undoubted formation of mantle and Hartig net, typical ectomycorrhizal structures [44]. 


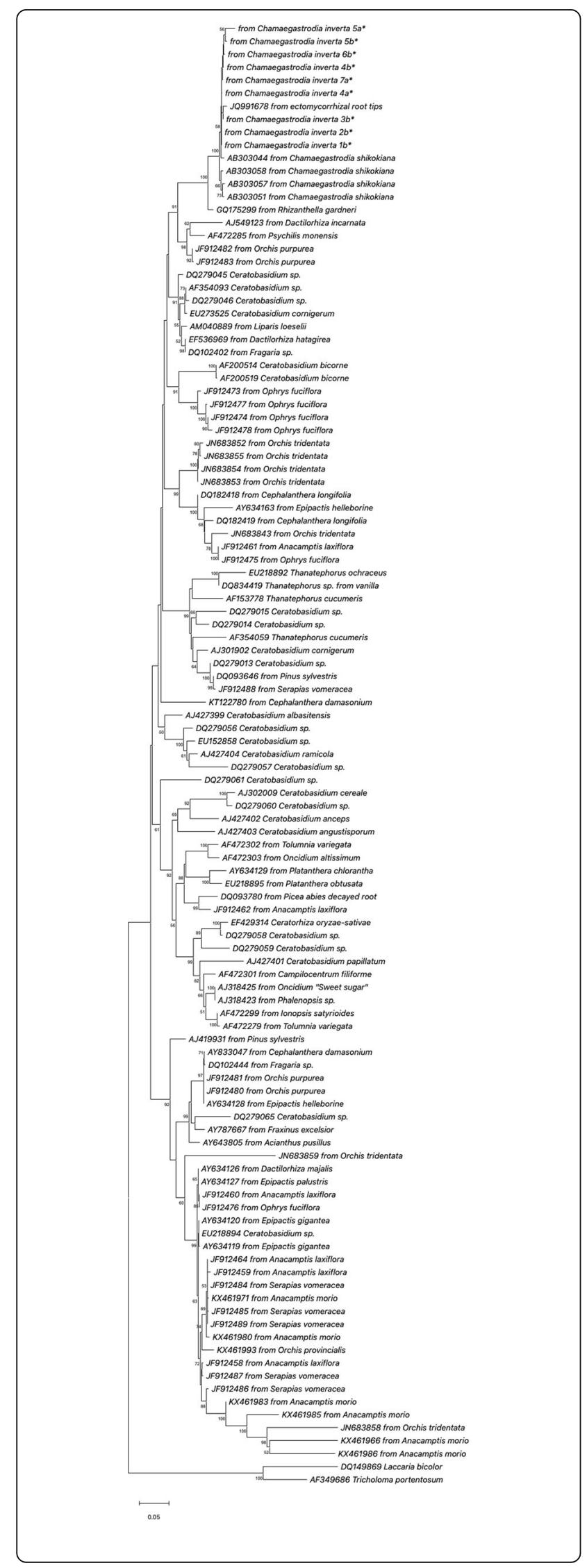

Fig. 3 Neighbour-joining phylogenetic tree showing the relationship between the Ceratobasidiaceae sequences obtained from Chamaegastrodia inverta $\left(^{*}\right)$ and selected database relatives. Kimura 2-parameter distances were used. Bootstrap values are based on percentages of 1000 replicates. The tree was rooted with Laccaria bicolor and Tricholoma portentosum as outgroups

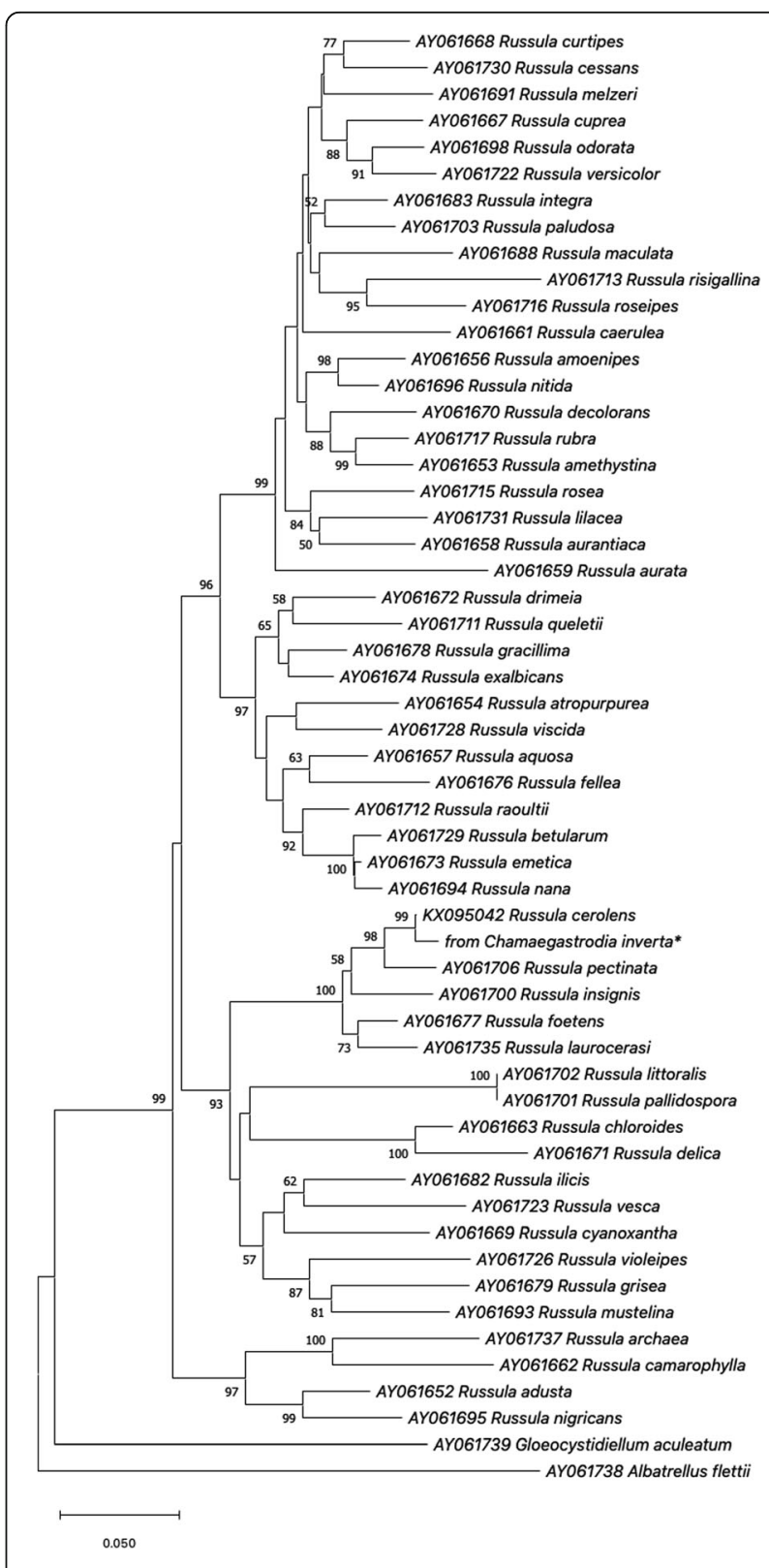

Fig. 4 Neighbour-joining phylogenetic tree showing the relationship between the Russula sequence obtained from Chamaegastrodia inverta $\left({ }^{*}\right)$ and selected database relatives. Kimura 2-parameter distances were used. Bootstrap values are based on percentages of 1000 replicates. The tree was rooted with Gloeocystidiellum aculeatum and Albatrellus flettii as outgroups 
Table 2 Fungal diversity molecularly detected in Chamaegastrodia inverta roots, from DNA extracted from isolated fungi

\begin{tabular}{|c|c|c|c|c|c|}
\hline C. inverta sample & GenBank code & Best BLAST match(es) & Accession code & Overlap length & $\%$ match \\
\hline \multirow[t]{2}{*}{$1(1) \mathrm{a}$} & MT278320 & Uncultured fungus & AB520571 & 1184 & $99 \%$ \\
\hline & & Mortierella alpina & KJ469836 & 1168 & $98 \%$ \\
\hline \multirow[t]{2}{*}{$1(1) \mathrm{C}$} & MT278321 & Uncultured fungus & AB520571 & 1194 & $99 \%$ \\
\hline & & Mortierella alpina & KJ469836 & 1177 & $99 \%$ \\
\hline \multirow[t]{2}{*}{$1(1) d$} & MT278322 & Uncultured fungus & AB520571 & 1203 & $99 \%$ \\
\hline & & Uncultured Mortierella & HG936573 & 1182 & $98 \%$ \\
\hline \multirow[t]{2}{*}{$1(1) \mathrm{e}$} & MT278323 & Uncultured fungus & AB520571 & 1994 & $99 \%$ \\
\hline & & Uncultured Mortierella & HG936573 & 1965 & $98 \%$ \\
\hline \multirow[t]{2}{*}{$1(2) a$} & MT278324 & Uncultured fungus & AB520571 & 1190 & $99 \%$ \\
\hline & & Uncultured Mortierella & HG936573 & 1170 & $98 \%$ \\
\hline \multirow[t]{2}{*}{$1(2) c$} & MT278325 & Uncultured fungus & AB520571 & 1229 & $99 \%$ \\
\hline & & Uncultured Mortierella & HG936573 & 1208 & $98 \%$ \\
\hline \multirow[t]{2}{*}{$1(2) \mathrm{e}$} & MT278326 & Uncultured fungus & AB520571 & 1214 & $99 \%$ \\
\hline & & Uncultured Mortierella & HG936573 & 1199 & $99 \%$ \\
\hline \multirow[t]{2}{*}{$1(2) \mathrm{g}$} & MT278327 & Fungal sp. strain & KU838618 & 1033 & $99 \%$ \\
\hline & & Phomopsis sp. & KF428571 & 1033 & $99 \%$ \\
\hline \multirow[t]{2}{*}{$1(3)$} & MT278328 & Uncultured fungus & AB520571 & 1190 & $98 \%$ \\
\hline & & Uncultured Mortierella & HG936573 & 1173 & $98 \%$ \\
\hline \multirow[t]{2}{*}{$1(3) \mathrm{a}$} & MT278329 & Uncultured fungus & KC222700 & 1037 & $98 \%$ \\
\hline & & Mortierella sp. & KX640303 & 1029 & $99 \%$ \\
\hline \multirow[t]{2}{*}{$1(3) b$} & MT278330 & Uncultured fungus & AB520571 & 1210 & $99 \%$ \\
\hline & & Uncultured Mortierella & HG936573 & 1192 & $98 \%$ \\
\hline $1(4)$ & MT278331 & Phomopsis sp. & KF428571 & 1050 & $99 \%$ \\
\hline $1(6) \mathrm{a}$ & MT278332 & Phomopsis sp. & KF428571 & 1040 & $99 \%$ \\
\hline \multirow[t]{2}{*}{$1(6) b$} & MT278333 & Uncultured fungus & AB520571 & 1218 & $99 \%$ \\
\hline & & Uncultured Mortierella & HG936573 & 1199 & $98 \%$ \\
\hline $1(6) c$ & MT278334 & Phomopsis sp. & KF428571 & 1055 & $99 \%$ \\
\hline \multirow[t]{3}{*}{$3(3) b$} & MT278335 & Uncultured fungus & KC222831 & 977 & $98 \%$ \\
\hline & & Diaporthales sp. & KF428606 & 972 & $99 \%$ \\
\hline & & Diaporthe sp. & FJ799941 & 952 & $96 \%$ \\
\hline \multirow[t]{3}{*}{$3(3) c$} & MT278336 & Uncultured fungus & KC222831 & 977 & $98 \%$ \\
\hline & & Diaporthales sp. & KF428606 & 972 & $99 \%$ \\
\hline & & Diaporthe sp. & FJ799941 & 946 & $96 \%$ \\
\hline \multirow[t]{2}{*}{$3(3) d$} & MT278337 & Diaporthales sp. & KF428606 & 972 & $99 \%$ \\
\hline & & Diaporthe sp. & FJ799941 & 944 & $96 \%$ \\
\hline \multirow[t]{2}{*}{$3(3)$ e } & MT278338 & Diaporthales sp. & KF428606 & 972 & $99 \%$ \\
\hline & & Diaporthe sp. & FJ799941 & 950 & $96 \%$ \\
\hline \multirow[t]{2}{*}{$3(4)$} & MT278339 & Uncultured fungus & KF296769 & 1127 & $98 \%$ \\
\hline & & Uncultured Leptodontidium & JF519497 & 1127 & $98 \%$ \\
\hline \multirow[t]{3}{*}{$3(4) b$} & MT278340 & Uncultured fungus & KF296769 & 1133 & $98 \%$ \\
\hline & & Uncultured Protoventuria & JQ346991 & 1133 & $98 \%$ \\
\hline & & Uncultured Leptodontidium & JF519497 & 1133 & $98 \%$ \\
\hline \multirow[t]{2}{*}{$4(3) b$} & MT278341 & Diaporthales sp. & KF428606 & 1002 & $100 \%$ \\
\hline & & Diaporthe sp. & FJ799941 & 979 & $97 \%$ \\
\hline
\end{tabular}


Table 2 Fungal diversity molecularly detected in Chamaegastrodia inverta roots, from DNA extracted from isolated fungi (Continued)

\begin{tabular}{|c|c|c|c|c|c|}
\hline C. inverta sample & GenBank code & Best BLAST match(es) & Accession code & Overlap length & $\%$ match \\
\hline \multirow[t]{2}{*}{$4(3) c$} & MT278342 & Uncultured fungus & AB520571 & 1195 & $99 \%$ \\
\hline & & Uncultured Mortierella & HG936573 & 1179 & $98 \%$ \\
\hline \multirow[t]{2}{*}{$4(3) d$} & MT278343 & Diaporthales sp. & KF428606 & 1002 & $100 \%$ \\
\hline & & Diaporthe sp. & FJ799941 & 987 & $97 \%$ \\
\hline $5(1) \mathrm{a}$ & MT278344 & Phomopsis sp. & KF428571 & 1048 & $99 \%$ \\
\hline $5(1) b$ & MT278345 & Phomopsis sp. & KF428571 & 1042 & $99 \%$ \\
\hline \multirow[t]{2}{*}{$5(3)$} & MT278346 & Uncultured fungus & AB520571 & 1177 & $98 \%$ \\
\hline & & Mortierella alpina & KJ469836 & 1164 & $98 \%$ \\
\hline $5(4) a$ & MT278347 & Chaetomium nigricolor & JF439467 & 1057 & $99 \%$ \\
\hline \multirow[t]{2}{*}{5 (Pel) } & MT278348 & Uncultured fungus & AB520571 & 1190 & $98 \%$ \\
\hline & & Uncultured Mortierella & HG936573 & 1173 & $98 \%$ \\
\hline \multirow[t]{2}{*}{$7(2) a$} & MT278349 & Fungal endophyte isolate & KR015900 & 1026 & $98 \%$ \\
\hline & & Phomopsis sp. & JQ341094 & 1020 & $99 \%$ \\
\hline \multirow[t]{2}{*}{$7(2) b$} & MT278350 & Fungal endophyte isolate & KR015900 & 1022 & $98 \%$ \\
\hline & & Phomopsis sp. & JQ341094 & 1020 & $98 \%$ \\
\hline \multirow[t]{2}{*}{$8(1)$} & MT278351 & Uncultured fungus & AB520586 & 479 & $84 \%$ \\
\hline & & Uncultured Mortierella & FJ197919 & 473 & $83 \%$ \\
\hline
\end{tabular}

BLAST search closest matches of fungal internal transcribed spacer DNA sequences amplified from C. inverta. In sample codes, first numbers (from 1 to 8 ) indicate the plant samples, numbers in brackets the root portions, letters the isolated fungal strain. Sample GenBank accession codes, accession codes for the closest GenBank matches, sequence identity, and overlap of each match are reported

Ectomycorrhizal taxa constitute a rare exception among Ceratobasidiaceae, the great majority of members within this fungal family, as well as Rhizoctonia-forming Agaricomycotina in general, being regarded as saprotrophs and plant pathogens $[28,31,43-45]$. The previously reported cases of tripartite relatioships C. shikokianaCeratobasidium-A. firma [28] and R. gardneri-Ceratobasidium-Melaleuca [44] involved ceratobasidioid fungi which were able to establish orchid mycorrhizas with fully mycoheterotrophic orchid species and ectomycorrhizas with autotrophic tree or shrub hosts simultaneously, the photosynthetic plant partner being the provider of carbon for the system. An additional example of ectomycorrhizal Ceratobasidiaceae was provided by the fungi isolated from the roots of the mixotrophic orchid Platanthera minor, which were also found to show ectomycorrhiza-forming ability on Pinus densiflora, the sole ectomycorrhizal tree species in the sampling sites in Japan [45]. The P. minor associated Ceratobasidium fungi formed a highly supported clade with mycobionts from $C$. shikokiana and $R$. gardneri in the phylogenetic analyses performed by Yagame et al. [45]. The Ceratobasidiaceae associated with C. inverta, in this study, are also closely related and cluster with the above mentioned ectomycorrhizal ceratobasidioid fungi from C. shikokiana and $R$. gardneri. It is therefore possible that $C$. inverta establishes a tripartite relationship with some of the surrounding autotrophic plants in the forest habitats where it grows, using the ceratobasidioid associated fungi to exploit the ectomycorrhizal plant as a carbon source. Further studies are necessary to test this hypothesis, by determining $C$. inverta natural abundance in ${ }^{13} \mathrm{C}$ and ${ }^{15} \mathrm{~N}$ compared with those of surrounding photosynthetic plants, in order to confirm and quantify the contribution of fungal source to the orchid carbon nutrition [46]. Besides, experiments of ectomycorrhiza formation on roots of potential tree hosts available in $C$. inverta habitats, using Ceratobasidiaceae isolated from the studied orchid as inoculum, would clarify the ability of the orchid fungal associates to establish ectomycorrhizal symbiosis with surrounding autotrophic partners. Our attempt of fungal isolation from pelotons extracted from the cortical cells of $C$. inverta roots was unsuccessful. The sole strain observed to apparently grow from a peloton isolated from orchid sample 5 was molecularly similar to an uncultured fungus detected in agricultural soil from Japan [47] and to a Mortierella sequence amplified from Zea mays field soil samples in Germany [48] (Table 2). This isolated mycelium may actually reflect a fungal contaminant from spore or a non-mycorrhizal root endophyte from hyphal fragment accidentally trapped in the cultured peloton. The difficulty in isolating in axenic culture the real $C$. inverta fungal symbionts from pelotons was confirmed by the result of isolation attempts from root fragments, which provided a number of ascomycetous and zygomycetous strains, but did not yield any ceratobasidioid basidiomycete. This result is in agreement with previous studies on C. shikokiana and $R$. 
gardneri, involving similar Ceratobasidiaceae mycorrhizal fungi. In the former study on C. shikokiana the authors reported that no fungal growth was observed on Czapek-Dox medium, which they normally used for saprobic fungi isolation, while active mycelial growth was obtained from pelotons cultured on a Modified Melin-Norkrans medium, specific for ectomycorrhizal fungi [28]. Similarly, in the study on $R$. gardneri, Bougoure et al. [44] found that isolation and growth of fungal pelotons from the roots of the studied orchid were mostly unsuccessful, with extracted hyphal coils failing to grow or colonies suddenly dying after initial growth. The absence of hyphal growth from $C$. inverta mycobiont extracted pelotons on PDA medium suggests that the analysed fungi belong to the ectomycorrhizal trophic group and may require very specific media to be isolated. However, the ecology and lifestyle of Ceratobasidiaceae associated with achlorophyllous mycoheterotrophic orchids is difficult to predict and generalize, and requires in-depth analyses to be understood, in every single association with different plant species. For instance, Bougoure et al. [49] showed that Ceratobasidiaceae associated with $R$. gardneri obtained carbon by both saprothrophic and mycorrhizal means, simultaneously. In the latter work, isotopically labelled tracers, ${ }^{13} \mathrm{CO}_{2}$ and double-labelled $\left[{ }^{13} \mathrm{C}-{ }^{15} \mathrm{~N}\right]$ glycine were used to assess the direction of carbon and nitrogen transfers between the plants involved in the investigated tripartite association via the fungal connections, showing that $R$. gardneri obtained nutrients from the associated mycorrhizal ceratobasidioid fungi, which were able to derive carbon not only from surrounding autotrophic shrubs via ectomycorrhizas, but also from soil organic matter via saprotrophic activity [49].

One out of the three analysed C. inverta young seedlings, sample 6 , showed an interesting association with another basidiomycete (Fig. 4) highly similar to Russula cerolens in GenBank from an unpublished study by $\mathrm{Ma}$ et al. on Russulaceae diversity in Heilongjiang Province, in China, and to sequences from specimens of $R$. insignis and $R$. pectinata collected in Europe [50]. The amplified Russula mycorrhizal fungus was co-occurring with Ceratobasiaceae in the roots of the same $C$. inverta individual (Table 1). Species in the large mushroom genus Russula are well documented as ecologically important ectomycorrhizal symbionts with forest tree species $[50,51]$. Russulaceae fungi have been found to be mycorrhizal partners of a variety of orchids belonging to different physiological types, such as the fully mycoheterotrophic species Corallorhiza maculata [11] and Dipodium hamiltonianum [52], the partially mycoheterotrophic orchids Epipactis microphylla [7] and Limodorum abortivum [53], as well as green photosynthetic Cypripedium species [54]. In a comprehensive study on mycorrhizal diversity in the fully mycoheterotrophic orchid genus Hexalectris, Kennedy et al. [55] found that $H$. brevicaulis collected in Mexico and $H$. grandiflora from USA displayed mixed associations with Russulaceae and Sebacinaceae symbionts. To our knowledge the simultaneous presence of ectomycorrhizal Russulaceae and Ceratobasidiaceae in the same achlorophyllous orchid species represents a new finding from the present work, where the two mycorrhizal fungi were even detected in the same $C$. inverta individual. This result supports the hypothesis of $C$. inverta preference for ectomycorrhizal fungi to establish trophic relationships that may also involve other plants interconnected by underground fungal network. This specificity toward ectomycorrhizal fungal partners needs to be confirmed with additional analyses on C. inverta samples from different localities. It is interesting that the presence of Russula in C. inverta roots was only detected at young seedling stage, while all analysed adult plants only yielded Ceratobasidiaceae sequences. It is possible that the analysed orchid species associates with different fungi during different stages of its development, as it was previously shown in a variety of orchids characterized by changing level of mycorrhizal specificity through life stages, from germinating seeds and protocorms to adult plants [5, 30]. Experiments using orchid seed baits buried in sites characterized by the presence of $C$. inverta populations may be crucial to identify fungal taxa able to stimulate seed germination and to sustain protocorm development in nature [56], as well as to clarify whether or not the identity of mycorrhizal fungi associating with $C$. inverta can be affected by the plant life stage.

Besides typical orchid mycorrhizal taxa, some other fungi with unclear functional roles were also detected in the studied orchid roots. They were mainly uncovered using the culture-dependent approach, thus demonstrating the importance of culture-based method for the accurate analysis of fungal community associated with orchid roots (Table 2). Among them, the most abundant were in the Mucoromycota, which represent an exceptional report as orchid associates, and were previously considered root pathogens or saprotrophic fungi in orchid dead cells [57]. Ascomycota from different families were more sporadically detected, the best matches for sequences amplified from $C$. inverta being fungi from various sources, including Phomopsis sp. from roots of Populus trees (Bonito et al. unpublished), Diaporthe sp. from leaves of Ipomoea philomega [58], uncultured Leptodontidium from roots of Fagus sylvatica (Schnecker et al. unpublished), and Chaetomium nigricolor from forest soil in Zijin Mountain, China [59] (Table 2). These ascomycetes may represent root fungal endophytes [43, 60]. However, some of them, such as Leptodontidium fungi, are very frequently selected during in vitro 
isolation or PCR amplification from orchid tissues using fungus-specific primers $[34,61,62]$. Further physiological characterization of these fungi is needed to understand whether they play any trophic role in their association with $C$. inverta.

\section{Conclusions}

Our results provide new insights on the spectrum of orchid-fungus symbiosis suggesting an unprecedented mixed association between the achlorophyllous forest orchid C. inverta and ectomycorrhizal fungi belonging to Ceratobasidiaceae and Russulaceae. This urges for more in-depth investigations of mycorrhizal diversity and physiology in the five orchid species belonging to the genus Chamaegastrodia, which may represent useful models to understand the evolution and specificity of mycoheterotrophic interactions, even if their rarity constitutes a challenge for performing detailed, large scale experiments.

\section{Methods}

\section{Orchid collection}

Chameagastrodia inverta root samples were collected in September 2015, from a forest with coniferous species of Pinus, mixed with various broad-leaved trees dominated by Eucalyptus sp. and Quercus sp., located in the western part of Kunming Botanical Garden, Kunming Institute of Botany, Chinese Academy of Sciences, Kunming, Yunnan Province, China. No permissions were necessary to collect plant samples, using a protocol that allows plant survival. Plants were identified by the authors. After harvesting the root material necessary for the study, plants were replaced in the sampling site, in the exact location where they were found. In total, eight orchid individuals were sampled, including 5 adult and completely developed plants, at the end of flowering stage, and 3 hypogeous young plants (seedlings) at an initial stage of development (Fig. 1a-d). Although the sampling size for the studied species was limited due to its rarity, small population size and the cryptic nature of its inflorescence, which is the only above ground organ, the investigated site provided a significant number of samples representing different life stages of the analysed orchid. All collected roots were washed under running water and carefully brushed in order to remove soil debris. Mycorrhizal morphology of fresh root samples was observed on thin cross-sections under a light microscope at 100 to 1000-fold magnification. Root fragments exhibiting high fungal colonization were immediately processed for fungal isolation. Part of root material was frozen in liquid nitrogen and stored at $-80^{\circ} \mathrm{C}$ for molecular analysis.

\section{Fungal isolation}

Isolation of fungi from fresh orchid root fragments was performed immediately after sampling. Single pelotons (hyphal coils within orchid root cells) were dissected from the outer cortex of $C$. inverta roots following Rasmussen [4], rinsed twice in double distilled water, transferred in $1 \mu \mathrm{l}$ water, and cultured on potato dextrose agar (PDA, Solarbio, Beijing, China) for both morphological and molecular identification.

Fungi were also isolated from root segments [41] surface-sterilized with consecutive washes of 1:5 sodium hypochlorite $(30 \mathrm{~s})$, rinsing in three changes of sterile water, cut in $3-5 \mathrm{~mm}$ long pieces, and cultured on PDA. Petri dishes were incubated at room temperature (20$25^{\circ} \mathrm{C}$ ) in the dark for up to 2 months to allow the development of slow-growing mycelia.

\section{Molecular identification of root fungal associates}

Both DNA from isolated fungi and total DNA from orchid root samples were extracted following the cetyltrimethyl ammonium bromide (CTAB) method [63].

Fungal ITS regions were amplified by polymerase chain reaction (PCR), using the primer pairs ITS1F/ITS4 [64] and ITS1-OF/ITS4-OF [65] in $50 \mu \mathrm{L}$ reaction volume, containing $38 \mu \mathrm{L}$ steril distilled water, $5 \mu \mathrm{L} 10 \times$ buffer $(100 \mathrm{mM}$ Tris- $\mathrm{HCl} \mathrm{pH} 8.3,500 \mathrm{mM} \mathrm{KCl}, 11 \mathrm{mM}$ $\mathrm{MgCl} 2,0.1 \%$ gelatin), $1 \mu \mathrm{L}$ of dNTP mixture of $10 \mathrm{mM}$ concentration, $0,25 \mu \mathrm{M}$ of each primer, $1.5 \mathrm{U}$ of RED TaqTM DNA polymerase (Sigma) and approximately $10 \mu \mathrm{g}$ of extracted genomic DNA. Amplifications were performed in a PerkinElmer/Cetus DNA thermal cycler, under the following thermal conditions: 1 cycle of $95^{\circ} \mathrm{C}$ for $5 \mathrm{~min}$ initial denaturation before thermocycling, 30 cycles of $94{ }^{\circ} \mathrm{C}$ for $40 \mathrm{~s}$ denaturation, $45 \mathrm{~s}$ annealing at various temperatures following Taylor \& McCormick [65], $72{ }^{\circ} \mathrm{C}$ for $40 \mathrm{~s}$ elongation, followed by 1 cycle of $72{ }^{\circ} \mathrm{C}$ for $7 \mathrm{~min}$ extension. The resulting PCR products were electrophoresed in 1\% agarose gel with ethidium bromide and purified with the QIAEX II Gel Extraction Kit (QIAGEN) following the manufacturer's instructions. Controls with no DNA were included in every amplification experiment in order to test for the presence of laboratory contamination from reagents and reaction buffers.

DNA sequencing was performed at the GENEWIZ Company, Tianjin, China.

Sequences were edited, assembled using the program Sequencher 4.1 for MacOS 9, and analysed with BLAST searches against the National Center for Biotechnology Information (NCBI) sequence database (GenBank) [66]. Fungal DNA sequences amplified from $C$. inverta were submitted to GenBank under accessions MT278309 - MT278351. 
Phylogenetic analysis was conducted with Mega v. 5.0 [67]. DNA sequences were aligned with Clustal X v. 2.0 [68] and neighbour-joining trees against selected database sequences were constructed using Kimura 2parameter distances, with bootstrapping of 1000 replicates [69]. Distinct phylogenetic analyses were performed for the phylogenetically distant fungi identified from the roots of investigated orchids. The ceratobasidioid fungi tree was rooted with Laccaria bicolor and Tricholoma portentosum, while Gloeocystidiellum aculeatum and Albatrellus flettii were used as outgroups to root the Russula fungi tree.

\section{Abbreviations}

CTAB: Cetyltrimethyl ammonium bromide; PCR: Polymerase chain reaction

\section{Acknowledgements}

We are grateful to Prof. Zhu Liang Yang for precious help in sampling and preliminary analysis. We thank Prof. Robert P. Borris, the Handling Editor Prof. Bala Rathinasabapathi, and the anonymous reviewers for critical and useful comments to the original version of this manuscript.

\section{Authors' contributions}

Conception and design of the research $L P$, acquisition of data $L P$, analysis and interpretation of data $L P, X W$, drafting the article $L P$, revising the article critically for important intellectual content XW, GV, WYG, TCW, YG, and VKG. All authors approved the manuscript version to be published.

\section{Funding}

Not applicable.

\section{Availability of data and materials}

The Fungal DNA sequences amplified during this study are available in GenBank under accessions MT278309 - MT278351. No permissions were necessary to collect plant samples, using a protocol that allows plant survival. Plants were identified by the authors. After harvesting the root material necessary for the study, plants were replaced in the sampling site, in the exact location where they were found.

\section{Ethics approval and consent to participate}

Not applicable.

\section{Consent for publication}

Not applicable.

\section{Competing interests}

The authors declare that they have no competing interests. Two of the authors, LP and VKG, are members of editorial board of this journal.

\section{Author details}

${ }^{1}$ School of Pharmaceutical Science and Technology, Health Sciences Platform, Tianjin University, 92 Weijin Road, Nankai District, Tianjin 300072, China. ${ }^{2}$ Department of Agricultural, Food and Forest Sciences, University of Palermo, Palermo, Italy. ${ }^{3}$ The Engineering Research Center of Southwest Bio-Pharmaceutical Resources, Ministry of Education, Guizhou University, Guiyang, China. ${ }^{4}$ Laboratory of Mycology, Institute of Botany, Academy of Sciences of Uzbekistan, Tashkent, Uzbekistan. ${ }^{5}$ AgroBioSciences and Chemical \& Biochemical Sciences Department, University Mohammed VI Polytechnic, Hay Moulay Rachid, Ben Guerir, Morocco.

Received: 15 April 2020 Accepted: 14 July 2020

Published online: 03 August 2020

\section{References}

1. Leake JR. The biology of mycoheterotrophic ('saprophytic') plants. Tansley review no. 69. New Phytol. 1994;127:171-216.

2. Bidartondo M. The evolutionary ecology of myco-heterotrophy. New Phytol. 2005;167:335-52.
3. Selosse MA, Roy M. Green plants that feed on fungi: facts and questions about mixotrophy. Trends Plant Sci. 2009;14:64-70.

4. Rasmussen HN. Terrestrial orchids: from seed to mycotrophic plant. Cambridge: Cambridge University press; 1995.

5. Jacquemyn H, Brys R, Cammue BPA, Honnay O, Lievens B. Mycorrhizal associations and reproductive isolation in three closely related Orchis species. Ann Bot. 2011;107:347-56.

6. Preiss K, Adam IKU, Gebauer G. Irradiance governs exploitation of fungi: fine-tuning of carbon gain by two partially mycoheterotrophic orchids. Proc R Soc Lond B Biol Sci. 2010;277:1333-6.

7. Selosse MA, Faccio A, Scappaticci P, Bonfante P. Chlorophyllous and achlorophyllous specimens of Epipactis microphylla (Neottieae, Orchidaceae) are associated with ectomycorrhizal septomycetes, including truffles. Microbiol Ecol. 2004;47:416-26.

8. Schiebold JMI, Bidartondo MI, Lenhard F, Makiola A, Gebauer G. Exploiting mycorrhizas in broad daylight: partial mycoheterotrophy is a common nutritional strategy in meadow orchids. J Ecol. 2018;106:168-78.

9. Merckx VSFT, Freudenstein JV, Kissling J, Christenhusz MJM, Stotler RE, Crandall-Stotler B, et al. Taxonomy and classification. In V. Merckx (Ed.), Mycoheterotrophy: the biology of plants living on fungi, pp. 19-101. New York: Springer; 2013

10. Smith SE, Read DJ. Mycorrhizal Symbiosis. 2nd ed. San Diego: Academic Press; 1997.

11. Taylor DL, Bruns TD. Independent, specialized invasions of ectomycorrhizal mutualism by two nonphotosynthetic orchids. Proc Natl Acad Sci USA. 1997;94:4510-5.

12. McKendrick SL, Leake JR, Read DJ. Symbiotic germination and development of myco-heterotrophic plants in nature: transfer of carbon from ectomycorrhizal Salix repens and Betula pendula to the orchid Corallorhiza trifida through shared hyphal connections. New Phytol. 2000;145:539-48.

13. Taylor DL, Bruns TD, Leake JR, Read DJ. Mycorrhizal specificity and function in myco-heterotrophic plants. In: Van der Heijden MGA, Sanders I, editors. Mycorrhizal ecology, Ecological Studies, vol. 157; 2002. p. 375-413.

14. Bidartondo MI, Burghardt B, Gebauer G, Bruns TD, Read DJ. Changing partners in the dark: isotopic and molecular evidence of ectomycorrhizal liaisons between forest orchids and trees. Proc R Soc Lond B Biol Sci. 2004; 271:1799-806.

15. Ogura-Tsujita Y, Yokoyama J, Miyoshi K, Yukawa T. Shifts in mycorrhizal fungi during the evolution of autotrophy to mycoheterotrophy in Cymbidium (Orchidaceae). Am J Bot. 2012;99:1158-76.

16. Pecoraro L, Huang LQ, Caruso T, Perotto S, Girlanda M, Cai L, Liu ZJ. Fungal diversity and specificity in Cephalanthera damasonium and C. Iongifolia (Orchidaceae) mycorrhizas. J Syst Evol. 2017;55:158-69.

17. Ogura-Tsujita Y, Gebauer G, Hashimoto T, Umata H, Yukawa T. Evidence for novel and specialized mycorrhizal parasitism: the orchid Gastrodia confusa gains carbon from saprotrophic Mycena. Proc Royal Soc Lond B. 2009;276:761-7.

18. Roy M, Yagame T, Yamato M, Iwase K, Heinz C, Faccio A, Bonfante P, Selosse M-A. Ectomycorrhizal Inocybe species associate with the mycoheterotrophic orchid Epipogium aphyllum but not its asexual propagules. Ann Bot. 2009: 104:595-610.

19. Ogura-Tsujita Y, Yukawa T. High mycorrhizal specificity in a widespread mycoheterotrophic plant, Eulophia zollingeri (Orchidaceae). Am J Bot. 2008; 95:93-7.

20. Dearnaley JDW. The fungal endophytes of Erythrorchis cassythoides - is this orchid saprophytic or parasitic? Aust Mycol. 2006:25:51-7.

21. Martos F, Dulormne M, Pailler T, Bonfante P, Faccio A, Fournel J, et al. Independent recruitment of saprotrophic fungi as mycorrhizal partners by tropical achlorophyllous orchids. New Phytol. 2009;184:668-81.

22. Dearnaley JWD, Bougoure JJ. Isotopic and molecular evidence for saprotrophic Marasmiaceae mycobionts in rhizomes of Gastrodia sesamoides. Fungal Ecol. 2010;3:288-94.

23. Yamato M, Yagame T, Suzuki A, Iwase K. Isolation and identification of mycorrhizal fungi associating with an achlorophyllous plant, Epipogium roseum (Orchidaceae). Mycoscience. 2005;46:73-7.

24. Yagame T, Yamato M, Mii M, Suzuki A, Iwase K. Developmental processes of achlorophyllous orchid, Epipogium roseum: from seed germination to flowering under symbiotic cultivation with mycorrhizal fungus. J Plant Res. 2007;120:229-36.

25. Selosse M-A, Martos F, Perry BA, Padamsee M, Roy M, Pailler T. Saprotrophic fungal mycorrhizal symbionts in achlorophyllous orchid. Finding treasures among the molecular scraps. Plant Signal Behav. 2010;5:1-5. 
26. Roy M, Watthana S, Stier A, Richard F, Vessabutr S, Selosse M-A. Two mycoheterotrophic orchids from Thailand tropical dipterocarpacean forests associate with a broad diversity of ectomycorrhizal fungi. BMC Biol. 2009;7:51.

27. Lee Y-I, Yang C-K, Gebauer G. The importance of associations with saprotrophic non-Rhizoctonia fungi among fully mycoheterotrophic orchids is currently under-estimated: novel evidence from sub-tropical Asia. Ann Bot. 2015;116:423-35.

28. Yagame T, Yamato M, Suzuki A, Iwase K. Ceratobasidiaceae mycorrhizal fungi isolated from nonphotosynthetic orchid Chamaegastrodia sikokiana. Mycorrhiza. 2008;18:97-101.

29. Seidenfaden G. The genus Chamaegastrodia (Orchidaceae). Nord J Bot. 1994;14:293-301.

30. Bidartondo MI, Read DJ. Fungal specificity bottlenecks during orchid germination and development. Mol Ecol. 2008;17:3707-16.

31. Rasmussen HN. Recent developments in the study of orchid mycorrhiza. Plant Soil. 2002;244:149-63.

32. Otero JT, Ackerman JD, Bayman P. Diversity and host specificity of endophytic Rhizoctonia-like fungi from tropical orchids. Am J Bot. 2002;89: 1852-8.

33. Jacquemyn H, Honnay O, Cammue BPA, Brys R, Lievens B. Low specificity and nested subset structure characterize mycorrhizal associations in five closely related species of the genus Orchis. Mol Ecol. 2010;19:4086-95.

34. Pecoraro L, Girlanda M, Kull T, Perini C, Perotto S. Analysis of fungal diversity in Orchis tridentata Scopoli. Central Eur J Biol. 2012;7:850-7.

35. Pereira OL, Kasuya MCM, Borges AC, de Araujo EF. Morphological and molecular characterization of mycorrhizal fungi isolated from neotropical orchids in Brazil. Can J Bot. 2005;83:54-65.

36. Otero JT, Bayman P, Ackerman JD. Variation in mycorrhizal performance in the epiphytic orchid Tolumnia variegata in vitro: the potential for natural selection. Evol Ecol. 2005;19:29-43.

37. Otero JT, Flanagan NS, Herre EA, Ackerman JD, Bayman P. Widespread mycorrhizal specificity correlates to mycorrhizal function in the neotropical, epiphytic orchid lonopsis utricularioides (Orchidaceae). Am J Bot. 2007;94: 1944-50.

38. Cameron DD, Leake JR, Read DJ. Mutualistic mycorrhiza in orchids: evidence from plant-fungus carbon and nitrogen transfers in the green-leaved terrestrial orchid Goodyera repens. New Phytol. 2006;171:405-16.

39. Shefferson RP, Cowden CC, McCormick MK, Yukawa T, Ogura-Tsujita Y, Hashimoto T. Evolution of host breadth in broad interactions: mycorrhizal specificity in east Asian and north American rattlesnake plantains (Goodyera spp.) and their fungal hosts. Mol Ecol. 2010;19:3008-17.

40. Suetsugu K, Yamato M, Matsubayashi J, Tayasu I. Comparative study of nutritional mode and mycorrhizal fungi in green and albino variants of Goodyera velutina, an orchid mainly utilizing saprotrophic rhizoctonia. Mol Ecol. 2019;28:4290-9.

41. Pecoraro L, Caruso T, Cai L, Gupta VK, Liu Z-J. Fungal networks and orchid distribution: new insights from above- and below-ground analyses of fungal communities. IMA Fungus. 2018;9(1):1-11.

42. Dearnaley JDW. Further advances in orchid mycorrhizal research. Mycorrhiza. 2007;17:475-86.

43. Dearnaley JDW, Martos F, Selosse MA. Orchid mycorrhizas: molecular ecology, physiology, evolution, and conservation aspects. In: Hock B, editor. Fungal associations. 2nd ed. Berlin: Springer-Verlag; 2012. p. 207-30.

44. Bougoure JJ, Ludwig M, Brundrett M, Grierson P. Identity and specificity of the fungi forming mycorrhizas with the rare myco-heterotrophic orchid Rhizanthella gardneri. Mycol Res. 2009;113:1097-106.

45. Yagame T, Orihara T, Selosse M-A, Yamato M, Iwase K. Mixotrophy of Platanthera minor, an orchid associated with ectomycorrhiza-forming Ceratobasidiaceae fungi. New Phytol. 2012;193:178-87.

46. Gebauer $\mathrm{G}$, Meyer M. ${ }^{15} \mathrm{~N}$ and ${ }^{13} \mathrm{C}$ natural abundance of autotrophic and mycoheterotrophic orchids provides insight into nitrogen and carbon gain from fungal associations. New Phytol. 2003;160:209-23.

47. Nishizawa T, Zhaorigetu KM, Sato Y, Kaneko N, Ohta H. Molecular characterization of fungal communities in non-tilled, cover-cropped upland Rice field soils. Microbes Environ. 2010;25(3):204-10.

48. Moll J, Hoppe B, König S, Wubet T, Buscot F, Krüger D. Spatial distribution of fungal communities in an arable soil. PLoS One. 2016;11(2):e0148130. https://doi.org/10.1371/journal.pone.0148130.

49. Bougoure JJ, Brundrett MC, Grierson PF. Carbon and nitrogen supply to the rare underground orchid Rhizanthella gardneri. New Phytol. 2010;186:94756.
50. Miller SL, Buyck B. Molecular phylogeny of the genus Russula in Europe with a comparison of modern infrageneric classifications. Mycol Res. 2002;106(3): 259-76.

51. Gardes M, Bruns TD. Community structure of ectomycorrhizal fungi in a Pinus muricata forest: above- and below-ground views. Can J Bot. 1996;74: 1572-83.

52. Dearnaley JDW, Le Brocque AF. Molecular identification of the primary root fungal endophytes of Dipodium hamiltonianum (yellow hyacinth orchid). Aust J Bot. 2006;54:487-91.

53. Girlanda M, Selosse MA, Cafasso D, et al. Inefficient photosynthesis in the Mediterranean orchid Limodorum abortivum is mirrored by specific association to ectomycorrhizal Russulaceae. Mol Ecol. 2006;15:491-504.

54. Shefferson RP, Weiss M, Kull T, Taylor DL. High specificity generally characterizes mycorrhizal association in rare lady's slipper orchids, genus Cypripedium. Mol Ecol. 2005;14:613-26.

55. Kennedy AH, Taylor DL, Watson LE. Mycorrhizal specificity in the fully mycoheterotrophic Hexalectris Raf. (Orchidaceae: Epidendroideae). Mol Ecol. 2011;20:1303-16.

56. Brundrett MC, Scade A, Batty AL, Dixon DW, Sivasithamparam K. Development of in situ and ex situ seed baiting techniques to detect mycorrhizal fungi from terrestrial orchid habitats. Mycol Res. 2003;107:121020.

57. Oja J, Kohout P, Tedersoo L, Kull T, Köljalg U. Temporal patterns of orchid mycorrhizal fungi in meadows and forests as revealed by 454 pyrosequencing. New Phytol. 2015;205:1608-18.

58. Van Bael SA, Fernandez-Marin H, Valencia MC, Rojas El, Wcislo WT, Herre EA Two fungal symbioses collide: endophytic fungi are not welcome in leafcutting ant gardens. Proc Royal Soc B Biol Sci. 2009;276(1666):2419-26.

59. Han GM, Feng XG, Jia Y, Wang CY, He XB, Zhou QY, Tian XJ. Isolation and evaluation of terrestrial fungi with algicidal ability from Zijin Mountain, Nanjing, China. J Microbiol. 2011;49:562.

60. Bayman P, Otero JT. Microbial endophytes of orchid roots. In: Schulz B, Boyle C, Sieber TN, editors. Microbial root endophytes, soil biology, vol. 9, part II. Berlin: Springer; 2006. p. 153-77.

61. Irwin MJ, Bougoure JJ, Dearnaley JDW. Pterostylis nutans (Orchidaceae) has a specific association with two Ceratobasidium root associated fungi across its range in eastern Australia. Mycoscience. 2007:48:231-9.

62. Liebel HT, Bidartondo MI, Preiss K, Segreto R, Stöckel M, Rodda M, Gebauer G. C and N stable isotope signatures reveal constraints to nutritional modes in orchids from the Mediterranean and Macaronesia. Am J Bot. 2010;97:90312.

63. Doyle JJ, Doyle JL. Isolation of plant DNA from fresh tissues. Focus. 1990;12: 13-5.

64. Gardes M, Bruns TD. ITS primers with enhanced specificity for basidiomycetes - applications to the identification of mycorrhizae and rusts. Mol Ecol. 1993;2:113-8.

65. Taylor DL, McCormick MK. Internal transcribed spacer primers and sequences for improved characterization of basidiomycetous orchid mycorrhizas. New Phytol. 2008;177:1020-33.

66. National Center for Biotechnology Information (NCBI). http://www.ncbi.nlm. nih.gov/BLAST/index.html. Accessed 20 Jan 2020.

67. Tamura K, Peterson D, Peterson N, Stecher G, Nei M, Kumar S. MEGA5: molecular evolutionary genetics analysis using maximum likelihood, evolutionary distance, and maximum parsimony methods. Mol Biol Evol. 2011;28:2731-9.

68. Larkin MA, Blackshields G, Brown NP, Chenna R, McGettigan PA, McWilliam $H$, Valentin F, et al. Clustal W and Clustal X version 2.0. Bioinformatics. 2007; 23:2947-8.

69. Felsenstein J. Confidence limits on phylogenies: an approach using the bootstrap. Evolution. 1985;39:783-91.

\section{Publisher's Note}

Springer Nature remains neutral with regard to jurisdictional claims in published maps and institutional affiliations. 